\title{
The Effect of Resin and Monoterpenes on Spore Germination and Growth in Fusarium circinatum
}

\author{
S. L. Slinski, F. Zakharov, and T. R. Gordon
}

First and third authors: Department of Plant Pathology, and second author: Department of Plant Sciences, University of California, Davis 95616.

Accepted for publication 29 July 2014

\section{ABSTRACT}

Slinski, S. L., Zakharov, F., and Gordon, T. R. 2015. The effect of resin and monoterpenes on spore germination and growth in Fusarium circinatum. Phytopathology 105:119-125.

Resin obtained from Pinus radiata and five monoterpene components of resin (limonene, $\alpha$-pinene, $\beta$-pinene, camphene, and myrcene) were tested to determine their effects on mycelial growth and germination and survival of spores of Fusarium circinatum, the cause of pitch canker in pine, and $F$. temperatum, which is interfertile with $F$. circinatum but not pathogenic to pine. Averaged across all treatments, F. temperatum sustained the greatest reduction in radial growth $(16.9 \pm 0.02 \%$ of control). The greatest reduction in dry weight also occurred in $F$. temperatum (11.7 \pm $0.01 \%$ of control), and all isolates of $F$. circinatum were significantly less affected $(P<0.05)$. Spore germination rates in a saturated atmosphere of monoterpenes were relatively high for all tested isolates but, when placed in direct contact with resin, spore survival was significantly greater for $F$. circinatum than for $F$. temperatum. Our results are consistent with the hypothesis that greater tolerance of resin is one factor distinguishing $F$. circinatum from the nonpathogenic F. temperatum. However, differential tolerance of monoterpene components of resin is not sufficient to explain the observed variation in virulence to pine in F. circinatum.
Forest trees are subjected to frequent challenges from insects and parasitic microorganisms. Anatomical defenses such as bark can prevent penetration by most microorganisms and, thus, infections are often facilitated by wounds (2). When a coniferous tree is wounded, resin stored under pressure in resin ducts, canals, blisters, or cells is directed to the site of the injury (6). A potential pathogen must be able to tolerate the toxic components in resin in order to invade and proliferate in a coniferous host. Conifer resin consists of a complex mixture of terpenoids, including volatile monoterpenes and sesquiterpenes and nonvolatile diterpenes (22). Pine trees deploy both a constitutive and induced resin response when challenged by insects or pathogens.

Constitutively produced resin will flow immediately to the site of insect feeding, mechanical damage, or pathogen invasion. Induced resinosis will then be activated and may enhance defense against invading pathogens. Monoterpene components of resin have documented antimicrobial properties. For example, cell membranes became leaky and respiration was inhibited in fungi exposed to $\alpha$ pinene $(1,29)$, and the fungal enzymes cellulase and pectin methyl esterase were inhibited in the presence of (S)-limonene and thymol (20). In Pinus sylvestris, the concentration of $\beta$-pinene in resin was reported to increase significantly after inoculation with Diplodia pinea, relative to mock-inoculated controls (30), suggesting that this compound may contribute to defense against fungal pathogens.

Abundant production of resin occurs in response to infection by Fusarium circinatum Nirenberg \& O'Donnell, the cause of pitch canker in pine (18) and Douglas-fir (13). Resin accumulates at the site of infection, where growth of the pathogen induces a lesion that can girdle the affected branch. Individual infections cause tip dieback on young branches, whereas multiple, coalescing lesions may lead to death of larger branches and even the entire tree (16).

Corresponding author: T. R. Gordon; E-mail address: trgordon@ucdavis.edu

http://dx.doi.org/10.1094/PHYTO-02-14-0027-R

(c) 2015 The American Phytopathological Society
In all cases, infection sites are heavily invested in resin. That this response of the host does not prevent development of an infection implies that $F$. circinatum manifests some degree of tolerance for the antimicrobial components of resin. This expectation is reinforced by the observation that $F$. circinatum grows within both constitutive and traumatic resin ducts (21).

$F$. circinatum is closely related to and interfertile with $F$. temperatum Scaufl. \& Munaut (23) (=F. subglutinans sensu lato) (7), which is both a pathogen and commensal associate of corn (Zea mays L.). F. temperatum has also been isolated from teosinte (Z. mays subsp. mexicana (Schrad.) H. H. Iltis), the wild progenitor of corn, in Mexico (7), where it co-occurs with many native pine species. Whereas $F$. temperatum is not virulent on pine (12), F. circinatum retains the capacity to colonize corn (27) and other grasses (28). This suggests that a common ancestor of these two species may have been associated with grasses, and that virulence to pine may be a relatively recent evolutionary innovation. If so, tolerance of the antimicrobial components of pine resin might be a characteristic that differentiates $F$. circinatum from $F$. temperatum. Furthermore, if inhibitory effects of resin are an important barrier to pathogenesis, quantitative differences in resin tolerance within $F$. circinatum might be predictive of differences in virulence to pine. The present study was undertaken to test these hypotheses. Our specific objectives were to assess the effect of resin and five monoterpene components of resin (limonene, $\alpha$ pinene, $\beta$-pinene, camphene, and myrcene) individually and as a mixture on radial growth, dry weight accumulation, spore germination, and spore survival in F. circinatum and F. temperatum. The monoterpenes selected were the main terpenoid constituents of resin in Monterey pine ( $P$. radiata D. Don) $(6,24)$, one of the pine species most susceptible to pitch canker.

\section{MATERIALS AND METHODS}

Composition of $\boldsymbol{P}$. radiata resin. Resin was collected from six 10 -year-old Monterey pine trees ( $P$. radiata) at the University of California Plant Pathology farm in Davis. Using a 1.3-cm- 
diameter drill bit, a hole was created approximately $1 \mathrm{~cm}$ deep, and a 7.4-ml glass vial was inserted into each hole and removed $24 \mathrm{~h}$ later. Resin obtained in this way was analyzed within $30 \mathrm{~min}$ after collection, as described below. Resin from each tree was analyzed separately.

A total ion chromatogram of monoterpenes in $P$. radiata resin was obtained using gas chromatography mass spectrometry (GCMS). Resin $(20 \mu \mathrm{l})$ was dissolved in $200 \mu \mathrm{l}$ of dichloromethane, and $1 \mu \mathrm{l}$ was injected in splitless mode into an Agilent 6890 gas chromatograph coupled to an Agilent 5975B quadrupole mass selective detector. GC-MS parameters were set as described by Flores et al. (10). Briefly, the injector temperature was set at $220^{\circ} \mathrm{C}$, and separation of volatiles was performed on a DB-5MS column ( $30 \mathrm{~m}$ by $0.25 \mathrm{~mm}$ by $0.25 \mu \mathrm{m})$, with helium as the carrier gas. The initial oven temperature was set at $40^{\circ} \mathrm{C}$ for $1 \mathrm{~min}$ and increased to $190^{\circ} \mathrm{C}$ at a rate of $2^{\circ} \mathrm{C} / \mathrm{min}$. The transfer-line temperature was set to $230^{\circ} \mathrm{C}$, the source temperature to $230^{\circ} \mathrm{C}$, and the quadrupole temperature to $150^{\circ} \mathrm{C}$; the ionization potential was 70 electron volts; and ionized mass fragments were continuously scanned from 30 to $300 \mathrm{~m} / \mathrm{z}$. Volatile compounds were identified by spectral match (Match Factor $\geq 900$ ) with the National Institute of Standards and Technology Mass Spectral Search Program (v. 2.0d) (26), and by comparing retention time and mass spectra of authentic standards obtained from Sigma-Aldrich (St. Louis).

Fungal isolates. Experiments designed to assess tolerance of monoterpene components of resin included one isolate associated with each of 10 somatic compatibility groups of $F$. circinatum, which collectively represent the extent of genetic variation and variation in virulence known to occur in California $(15,17$; T. R. Gordon, unpublished data). For comparison, each experiment also included an isolate of $F$. temperatum (GL 52) obtained from teosinte (Z. mays subsp. mexicana (Schrad.) H. H. Iltis) in Mexico (Table 1). GL 52 was originally identified as $F$. subglutinans (7) but was subsequently recognized as F. temperatum, following the recent description of that species (23). Three additional isolates of F. subglutinans sensu lato obtained from Zea spp. in Mexico (7) were also determined to be $F$. temperatum, and were included in this study to evaluate intraspecific variation in tolerance of $\beta$-pinene. Finally, progeny derived from a hybrid cross between $F$. circinatum and $F$. temperatum (12) were tested to assess variation in tolerance of $\beta$-pinene among strains known to vary in virulence to pine (Table 1). All isolates are maintained in a collection in the Department of Plant Pathology at the University of California-Davis and are available on request from the corresponding author.

Spore germination. Spores for germination tests were obtained from cultures grown on potato dextrose agar (PDA) and maintained at room temperature $\left(21\right.$ to $\left.24^{\circ} \mathrm{C}\right)$ for 1 week. A sterile, bent glass rod was used to disrupt cultures and suspend mycelium and spores in approximately $20 \mathrm{ml}$ of sterile water. The resulting suspension was passed through four layers of sterile cheesecloth. The density of spores was estimated using a hemocytometer and adjusted to 50 spores/ $\mu$ by addition of sterile water. This suspension $(1 \mu \mathrm{l})$ was spread over the surface of PDA in a glass petri plate (100 $\mathrm{mm}$ in diameter by $15 \mathrm{~mm}$ deep). A monoterpene $(250 \mu \mathrm{l})$ was placed in a polypropylene cap $(15 \mathrm{~mm}$ in diameter by $7 \mathrm{~mm}$ deep), which was positioned at the center of each petri plate before the agar solidified. In this way, germinating spores were exposed to a saturated atmosphere of the test monoterpene. The chemicals ( $>95 \%$ purity) used for this experiment were camphene and myrcene and a racemic mixture of the $(+)$ and $(-)$ forms of $\alpha$-pinene, $\beta$-pinene, and limonene (Acros Organics, Thermo Fisher Scientific, NJ). The monoterpene mixture included $\alpha$-pinene, $\beta$-pinene, limonene, camphene, and myrcene in a ratio of $66: 28.5: 1.5: 2: 2$, which approximates the ratio of these compounds in $P$. radiata resin (6). Control plates were set up in the same manner, except that no monoterpene was added to the cap at the center of the petri plate. Plates correspond-

TABLE 1. Host and geographic origin of isolates of Fusarium circinatum and F. temperatum

\begin{tabular}{|c|c|c|c|c|}
\hline Strain & $\mathrm{SCG}^{\mathrm{w}}$ & Species $^{\mathrm{x}}$ & $\operatorname{Host}^{\mathrm{y}}$ & Origin $^{z}$ \\
\hline GL 56 & 1 & F. circinatum & Pinus radiata & Santa Cruz, CA \\
\hline GL 1321 & 2 & F. circinatum & $P$. radiata & Sonoma, CA \\
\hline GL 290 & 3 & F. circinatum & P. radiata & San Luis Obispo, CA \\
\hline GL 301 & 4 & F. circinatum & Pseudotsuga menziesii & Santa Cruz, CA \\
\hline GL 311 & 5 & F. circinatum & $P$. radiata & Los Angeles, CA \\
\hline GL 100 & 6 & F. circinatum & P. radiata & Monterey, CA \\
\hline GL 1325 & 7 & F. circinatum & P. radiata & Santa Cruz, CA \\
\hline GL 1326 & 8 & F. circinatum & P. radiata & San Luis Obispo, CA \\
\hline GL 314 & 9 & F. circinatum & P. radiata & San Diego, CA \\
\hline GL 58 & 10 & F. circinatum & $P$. radiata & Monterey, CA \\
\hline GL 52 & ND & F. temperatum & Zea mays subsp. mexicana & Mexico \\
\hline Fst 10 & ND & F. temperatum & Z. diploperennis & Mexico \\
\hline Fst 26 & ND & F. temperatum & Z. mays subsp. mexicana & Mexico \\
\hline Fst 29 & ND & F. temperatum & Z. mays subsp. mexicana & Mexico \\
\hline GL 343 & 1 & F. circinatum & $P$. radiata & Santa Cruz, CA \\
\hline GL 685 & ND & Progeny & NA & Laboratory cross \\
\hline GL 686 & ND & Progeny & NA & Laboratory cross \\
\hline GL 687 & ND & Progeny & NA & Laboratory cross \\
\hline GL 688 & ND & Progeny & NA & Laboratory cross \\
\hline GL 690 & ND & Progeny & NA & Laboratory cross \\
\hline GL 691 & ND & Progeny & NA & Laboratory cross \\
\hline GL 693 & ND & Progeny & NA & Laboratory cross \\
\hline GL 694 & ND & Progeny & NA & Laboratory cross \\
\hline GL 696 & ND & Progeny & NA & Laboratory cross \\
\hline GL 697 & ND & Progeny & NA & Laboratory cross \\
\hline GL 698 & ND & Progeny & NA & Laboratory cross \\
\hline GL 700 & ND & Progeny & NA & Laboratory cross \\
\hline GL 702 & ND & Progeny & NA & Laboratory cross \\
\hline GL 703 & ND & Progeny & NA & Laboratory cross \\
\hline
\end{tabular}

" Somatic compatibility group (SCG) to which the isolate is assigned; ND = not determined.

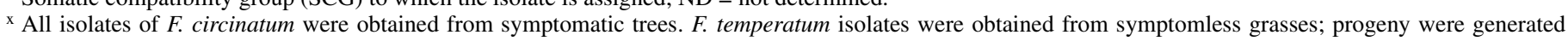
from a back cross of an $\mathrm{F}_{1}$ hybrid (GL $52 \times$ GL 343) to the $F$. circinatum parent (GL 343), as described by Friel et al. (12).

${ }^{\mathrm{y}}$ Host from which the fungus was isolated; NA = not applicable.

${ }^{\mathrm{z}}$ Location where the isolate was collected. 
ing to each treatment were placed in separate plastic containers (32.5 cm long, $23.0 \mathrm{~cm}$ wide, and $10.1 \mathrm{~cm}$ deep) (Pioneer Plastics, North Dixon, KY), all of which were maintained in the dark for $18 \mathrm{~h}$ in an incubator set at $25^{\circ} \mathrm{C}$. An incubation period of $18 \mathrm{~h}$ was chosen because it was determined to be the minimum time required for germination of $\geq 99 \%$ of spores in control plates (data not shown). A spore with a germ tube equal to or greater than the length of the spore was considered germinated. An experiment included four plates of each isolate for each treatment. The experiment was conducted twice.

Radial growth. To evaluate growth in a monoterpene-saturated atmosphere, glass petri plates containing PDA were set up as described for the previous experiment but with the cap placed at the edge of the plate. A 3-mm-diameter plug removed from the margin of an actively growing colony on PDA was placed at the center of a plate, and $250 \mu \mathrm{l}$ of one monoterpene (or mixture of monoterpenes) was deposited into the cap; nothing was placed in the cap in control plates. An experiment included six treatments: limonene, $\alpha$-pinene, $\beta$-pinene, camphene, myrcene, a monoterpene mixture (as described above), and a control. Each treatment was represented by four plates, which were placed in a plastic container and maintained in the dark at $25^{\circ} \mathrm{C}$, as described above. After 1 week, colony diameter was calculated as the average of measurements taken on two perpendicular axes. The effect of treatment was determined by expressing colony diameter of isolates exposed to monoterpenes as a percentage of untreated controls. The experiment was conducted twice.

Dry weight. The effect of a monoterpene-saturated atmosphere on biomass accumulation (= dry weight) was evaluated using PDA in glass petri plates with $250 \mu \mathrm{l}$ of a monoterpene (or mixture of monoterpenes) placed in a cap, as described for the radial growth experiment. In this case, a sterile, preweighed, $0.22-\mu \mathrm{m}$ polyethersulfone membrane filter (EMD Millipore, Billerica, MA) was placed on the surface of each plate and a 3-mm-diameter plug of colonized PDA from the margin of a growing colony was placed on the membrane. Each experiment included six treatments in which the cap was filled with one of the following: limonene, $\alpha$-pinene, $\beta$-pinene, camphene, myrcene, or a monoterpene mixture (as described above); nothing was placed in the cap on control plates. Each treatment was represented by four plates, which were placed in a plastic container and maintained at $25^{\circ} \mathrm{C}$ in the dark, as described above. After 1 week, filters were removed, placed in a drying oven at $70^{\circ} \mathrm{C}$ for $24 \mathrm{~h}$, and thereafter weighed to the nearest milligram. The effect of treatment was determined by expressing the dry weight of isolates exposed to monoterpenes as a percentage of untreated controls. The experiment was conducted twice.

Spore survival in resin. Resin was collected from 10-year-old Monterey pine trees $(P$. radiata) at the University of California Plant Pathology farm in Davis, as described above. For each experiment, resin was pooled from 8 to 10 individual trees and deployed in experiments within $30 \mathrm{~min}$ of collection. Spore suspensions were prepared as previously described and 100 spores were placed on a sterile, 5-mm disc of Whatman grade 4 filter paper (Whatman Inc., Sanford, ME). Each inoculated disk was placed into one well of a 24-well cell culture plate (BD Biosciences, San Jose, CA), and immediately covered with $200 \mu \mathrm{l}$ of resin. Control filters were placed in a well with no resin added. Cell culture plates were maintained in the dark at $25^{\circ} \mathrm{C}$ for 7 days. Thereafter, filter papers were removed and placed on Komada's selective medium (19). Each disk was scored as positive or negative for growth of $F$. circinatum after 2 weeks at room temperature (21 to $24^{\circ} \mathrm{C}$ ). Each treatment was replicated four times. The experiment was conducted three times.

Virulence assay. For each isolate to be tested, spore suspensions were prepared as described above and diluted with sterile water to obtain a density of 50 spores/ $\mu l$. An inoculation was performed by depositing $5 \mu \mathrm{l}$ of a spore suspension into a shallow wound, approximately $1.6 \mathrm{~mm}$ in diameter, which penetrated the bark on a branch of $P$. radiata, as described by Gordon et al. (14). Each isolate was tested on two branches on each of five trees. The experiment was conducted twice, each time with a different set of five trees.

Data analysis. The significance of treatment effects on spore germination, radial growth and dry weight among isolates was tested with analysis of variance (ANOVA), as implemented in Proc Mixed (SAS release 9.1; SAS Institute, Cary, NC). In these analyses, isolate and treatment were coded as fixed effects; and replication, block (repeats of the experiment), and interaction terms as random effects. The significance of random effects was evaluated with a $\chi^{2}$ test to compare residual log-likelihood values obtained with and without the random term included in the model. Percentages were subjected to an arcsin square root transformation prior to analysis. Where significant $F$ values were obtained, Tukey's all pairwise comparison test, which includes a correction for multiple comparisons, was used to assess the significance of differences between means. Regression analyses were performed using Proc Reg (SAS release 9.1).

\section{RESULTS}

Composition of $\boldsymbol{P}$. radiata resin. Analysis of volatile components of resin from $P$. radiata showed (+)- $\alpha$-pinene to be the most abundant monoterpene, followed by (-)- $\beta$-pinene. Limonene, camphene, and myrcene were the least abundant (Fig. 1). This pattern was observed in all six of the tested trees. All of these monoterpenes have been previously described in the resin of $P$. radiata, with a predominance of $\alpha$ - and $\beta$-pinene $(3,4,25)$.

Spore germination. In the absence of monoterpenes, not less than $97.5 \%$ of $F$. temperatum and F. circinatum spores germinated (Table 2). In the presence of a saturated atmosphere of monoterpenes, germination rates for $F$. circinatum were 71.6 to $99.9 \%$ across all isolates and treatments. For $F$. temperatum, spore germination rates were as low as $59.2 \%$ and as high as $98.0 \%$ (Table 2). ANOVA showed the main effects of isolate and treatment to be significant $(P<0.001$ in both cases), whereas block and replication were not significant $(P>0.999$ and $P=0.752$, respectively). The block-treatment, block-isolate, block-isolatetreatment, and treatment-isolate interactions were also not significant $(P \geq 0.193)$. Averaged across treatments, $F$. temperatum had a spore germination rate of $88.9 \%$, which was significantly lower $(P<0.05)$ than most but not all isolates of $F$. circinatum, for which mean germination rates were 85.0 to $97.3 \%$ (Table 2). Averaged across isolates, $\beta$-pinene, limonene, and camphene were significantly more inhibitory than $\alpha$-pinene, myrcene, or the mixture of monoterpenes $(P<0.05)$. Exposure to $\beta$-pinene had

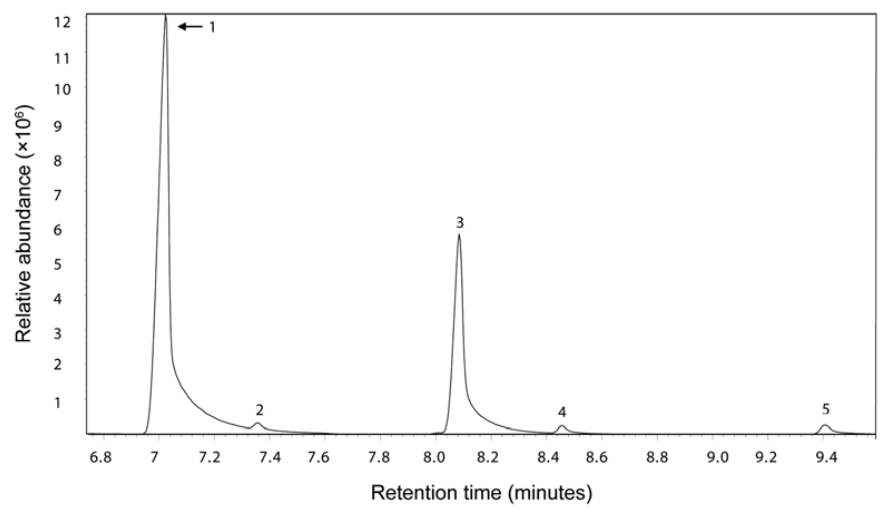

Fig. 1. Total ion chromatogram of monoterpenes in Pinus radiata resin analyzed by gas chromatography mass spectrometry. Peaks correspond to (+)- $\alpha$-pinene (1), camphene (2), (-)- $\beta$-pinene (3), myrcene (4), and limonene (5). 
TABLE 2. Germination of spores of Fusarium circinatum and F. temperatum in a saturated atmosphere of monoterpenes

Spores germinated $(\%)^{\mathrm{x}}$

\begin{tabular}{|c|c|c|c|c|c|c|c|c|}
\hline Isolate $^{w}$ & $\alpha$-Pinene & $\beta$-Pinene & Limonene & Myrcene & Camphene & Mixture & Control & Isolate mean ${ }^{\mathrm{y}}$ \\
\hline GL 290 & $98.6( \pm 0.4) \mathrm{ab}$ & $95.1( \pm 0.8) \mathrm{a}$ & $93.5( \pm 0.9) \mathrm{a}$ & $99.9( \pm 0.6) \mathrm{a}$ & $92.6( \pm 4.2) \mathrm{ab}$ & $99.2( \pm 2.5) \mathrm{a}$ & $100( \pm 0.0) \mathrm{a}$ & $97.3( \pm 0.4) \mathrm{a}$ \\
\hline GL 314 & $98.8( \pm 0.4) \mathrm{ab}$ & $95.8( \pm 0.9) \mathrm{a}$ & $87.8( \pm 1.0) \mathrm{a}$ & $99.9( \pm 0.7) \mathrm{a}$ & $92.6( \pm 1.1) \mathrm{ab}$ & $97.2( \pm 1.3) \mathrm{a}$ & $100( \pm 0.0) \mathrm{a}$ & $96.5( \pm 0.4) \mathrm{a}$ \\
\hline GL 58 & $98.8( \pm 0.7) \mathrm{ab}$ & $92.4( \pm 0.8) \mathrm{a}$ & $90.7( \pm 0.4) \mathrm{a}$ & $99.9( \pm 0.4) \mathrm{a}$ & $94.2( \pm 3.3) \mathrm{a}$ & $97.7( \pm 1.7) \mathrm{a}$ & $98.8( \pm 1.2) \mathrm{a}$ & $96.5( \pm 0.4) \mathrm{a}$ \\
\hline GL 100 & $99.6( \pm 0.5) \mathrm{a}$ & $91.2( \pm 2.4) \mathrm{a}$ & $90.1( \pm 1.9) \mathrm{a}$ & $99.9( \pm 0.7) \mathrm{a}$ & $85.8( \pm 3.8) a b c$ & $99.3( \pm 2.4) \mathrm{a}$ & $100.0( \pm 0.0) \mathrm{a}$ & $96.3( \pm 0.7) \mathrm{a}$ \\
\hline GL 301 & $98.2( \pm 1.7) \mathrm{ab}$ & $91.5( \pm 0.6) \mathrm{a}$ & $90.1( \pm 1.4) \mathrm{a}$ & $99.4( \pm 1.1) \mathrm{a}$ & $93.5( \pm 3.3) \mathrm{ab}$ & $98.8( \pm 2.3) \mathrm{a}$ & $100.0( \pm 0.0) \mathrm{a}$ & $96.1( \pm 0.5) \mathrm{a}$ \\
\hline GL 1325 & $97.9( \pm 0.8) \mathrm{ab}$ & $91.8( \pm 1.4) \mathrm{a}$ & $90.8( \pm 1.8) \mathrm{a}$ & $98.6( \pm 1.7) \mathrm{a}$ & $90.1( \pm 1.5) \mathrm{abc}$ & $98.5( \pm 1.8) \mathrm{a}$ & $98.9( \pm 1.1) \mathrm{a}$ & $95.5( \pm 0.5) \mathrm{a}$ \\
\hline GL 1326 & $99.4( \pm 0.3)$ a & $88.7( \pm 1.5) \mathrm{a}$ & $89.3( \pm 0.5) \mathrm{a}$ & $96.4( \pm 1.9) \mathrm{ab}$ & $87.8( \pm 0.8)$ abc & $98.0( \pm 1.7) \mathrm{a}$ & $97.5( \pm 0.5) \mathrm{a}$ & $94.4( \pm 0.4) \mathrm{ab}$ \\
\hline GL 56 & $89.0( \pm 0.4) b$ & $82.2( \pm 0.5) \mathrm{ab}$ & $84.5( \pm 1.9) \mathrm{a}$ & $90.7( \pm 0.9) b$ & $71.6( \pm 2.5) \mathrm{c}$ & $89.9( \pm 4.6) \mathrm{a}$ & $99.4( \pm 0.6) \mathrm{a}$ & $85.0( \pm 0.5) \mathrm{c}$ \\
\hline $\operatorname{Mean}^{z}$ & $97.2( \pm 0.9) \mathrm{A}$ & $88.8( \pm 3.2) \mathrm{B}$ & $90.5( \pm 0.9) \mathrm{B}$ & $98.2( \pm 0.8) \mathrm{A}$ & $87.4( \pm 2.2) \mathrm{B}$ & $97.2( \pm 0.8) \mathrm{A}$ & $\ldots$ & $\ldots$ \\
\hline
\end{tabular}

${ }^{\mathrm{w}} \mathrm{GL} 52$ is an isolate of F. temperatum; all others are isolates of $F$. circinatum, each of which corresponds to one of ten somatic compatibility groups known to occur in California.

${ }^{x}$ Spores were incubated for $18 \mathrm{~h}$ in the presence of a single monoterpene or a mixture of five monoterpenes. Each entry corresponds to the mean of eight replications ( \pm standard error). Means in the same column followed by a common lowercase letter were not significantly different at $P=0.05$, based on Tukey's all pairwise comparison test, which includes a correction for multiple comparisons.

${ }^{y}$ Analysis of variance indicated that the isolate-treatment interaction was not significant; therefore, comparisons were made between means for isolates, averaged across all treatments. Means followed by a common lowercase letter were not significantly different at $P=0.05$, based on Tukey's all pairwise comparison test, which includes a correction for multiple comparisons.

${ }^{\mathrm{z}}$ Analysis of variance indicated that the isolate-treatment interaction was not significant; therefore, comparisons were made between means for treatments averaged across all isolates. Means followed by a common uppercase letter were not significantly different at $P=0.05$, based on Tukey's all pairwise comparison test, which includes a correction for multiple comparisons.

TABLE 3. Radial growth of Fusarium circinatum and F. temperatum in the presence of monoterpenes

\begin{tabular}{|c|c|c|c|c|c|c|c|}
\hline \multirow[b]{2}{*}{ Isolate $^{x}$} & \multicolumn{7}{|c|}{ Control $(\%)^{\mathrm{w}}$} \\
\hline & $\alpha$-Pinene & $\beta$-Pinene & Limonene & Myrcene & Camphene & Mixture & Isolate mean ${ }^{y}$ \\
\hline GL 58 & $43.3( \pm 0.00) \mathrm{a}$ & $37.3( \pm 0.04) \mathrm{a}$ & $38.5( \pm 0.04) \mathrm{a}$ & $41.5( \pm 0.01) \mathrm{a}$ & $34.6( \pm 0.03) \mathrm{a}$ & $41.2( \pm 0.03) \mathrm{ab}$ & $39.4( \pm 0.01) \mathrm{a}$ \\
\hline GL 301 & $43.1( \pm 0.02) \mathrm{a}$ & $33.0( \pm 0.01) \mathrm{b}$ & $33.1( \pm 0.01) b$ & $41.6( \pm 0.05) \mathrm{a}$ & $30.7( \pm 0.02) b$ & $41.4( \pm 0.01) \mathrm{ab}$ & $37.1( \pm 0.01) b$ \\
\hline GL 311 & $37.4( \pm 0.02) b$ & $31.4( \pm 0.03) b$ & $29.4( \pm 0.00) b c$ & $37.6( \pm 0.02) \mathrm{ab}$ & $30.0( \pm 0.02) \mathrm{b}$ & $39.2( \pm 0.02) b$ & $34.1( \pm 0.01) \mathrm{c}$ \\
\hline GL 1326 & $41.2( \pm 0.01) \mathrm{ab}$ & $27.3( \pm 0.03) \mathrm{c}$ & $25.0( \pm 0.01) \mathrm{d}$ & $37.3( \pm 0.01) b c$ & $28.7( \pm 0.00) b c$ & $54.0( \pm 0.07) \mathrm{a}$ & $33.9( \pm 0.01) \mathrm{c}$ \\
\hline GL 56 & $34.9( \pm 0.01) \mathrm{c}$ & $24.6( \pm 0.02) \mathrm{d}$ & $23.1( \pm 0.00) \mathrm{d}$ & $31.7( \pm 0.01) \mathrm{cd}$ & $22.6( \pm 0.01) \mathrm{d}$ & $36.8( \pm 0.02) b$ & $28.8( \pm 0.01) \mathrm{d}$ \\
\hline GL 1325 & $28.8( \pm 0.01) \mathrm{d}$ & $23.5( \pm 0.01) \mathrm{d}$ & $23.6( \pm 0.02) \mathrm{d}$ & $27.3( \pm 0.02) \mathrm{d}$ & $21.3( \pm 0.02) \mathrm{d}$ & $25.3( \pm 0.03) \mathrm{c}$ & $27.5( \pm 0.01) \mathrm{d}$ \\
\hline GL 1321 & $32.4( \pm 0.01) \mathrm{cd}$ & $25.4( \pm 0.01) \mathrm{d}$ & $26.4( \pm 0.01) \mathrm{cd}$ & $32.1( \pm 0.00) \mathrm{cd}$ & $26.2( \pm 0.00) \mathrm{c}$ & $29.0( \pm 0.00) \mathrm{c}$ & $27.4( \pm 0.02) d$ \\
\hline GL 52 & $18.6( \pm 0.04) \mathrm{e}$ & $18.4( \pm 0.06) \mathrm{e}$ & $14.1( \pm 0.02) \mathrm{e}$ & $20.9( \pm 0.01) \mathrm{e}$ & $11.0( \pm 0.00) \mathrm{e}$ & $19.0( \pm 0.01) \mathrm{d}$ & $16.9( \pm 0.02) \mathrm{e}$ \\
\hline $\operatorname{Mean}^{2}$ & $34.0( \pm 0.01) \mathrm{AB}$ & $28.0( \pm 0.01) \mathrm{C}$ & $26.5( \pm 0.01) \mathrm{D}$ & $33.1( \pm 0.01) \mathrm{B}$ & $26.0( \pm 0.01) \mathrm{D}$ & $34.5( \pm 0.01) \mathrm{A}$ & $\ldots$ \\
\hline
\end{tabular}

${ }^{\mathrm{w}}$ Isolates were incubated for 7 days in the presence of a single monoterpene or a mixture of five monoterpenes. Controls were grown in the same manner as treated isolates but without the presence of monoterpenes. Each entry corresponds to the mean percent reduction in radial growth ( \pm standard error) relative to the same isolate not exposed to monoterpenes $(n=8)$. Means in the same column followed by a common lowercase letter were not significantly different at $P=0.05$, based on Tukey's all pairwise comparison test, which includes a correction for multiple comparisons.

${ }^{x} \mathrm{GL} 52$ is an isolate of F. temperatum; all others are isolates of F. circinatum, each of which corresponds to one of ten somatic compatibility groups known to occur in California.

${ }^{y}$ Analysis of variance indicated that the isolate-treatment interaction was not significant; therefore, comparisons were made between means for isolates, averaged across all treatments. Means followed by a common lowercase letter were not significantly different at $P=0.05$, based on Tukey's all pairwise comparison test, which includes a correction for multiple comparisons.

${ }^{z}$ Analysis of variance indicated that the isolate-treatment interaction was not significant; therefore, comparisons were made between means for treatments, averaged across all isolates. Means followed by a common uppercase letter were not significantly different at $P=0.05$, based on Tukey's all pairwise comparison test, which includes a correction for multiple comparisons.

the greatest differential effect on spore germination (59.2 to $96.6 \%$ across isolates) and provided the clearest distinction between F. circinatum and F. temperatum (Table 2).

Radial growth. In a saturated atmosphere of monoterpenes, radial growth rates were 11.0 to $20.9 \%$ of control for $F$. temperatum and 21.3 to $54.0 \%$ of control across all $F$. circinatum isolates (Table 3). ANOVA revealed the main effects of isolate and treatment to be significant $(P<0.001$ in both cases). The effects of block, replication, and all interactions were not significant $(P \geq 0.114)$. Averaged across all treatments, $F$. temperatum sustained the greatest reduction in radial growth $(16.9 \%$ of control). This effect was significantly greater than observed in any isolate of $F$. circinatum, for which radial growth was 27.4 to $39.4 \%$ of controls (Table 3). Examined individually, all treatments revealed significant differences between isolates (Table 3). Averaged across isolates, the strongest treatment effects were caused by limonene and camphene, which reduced radial growth to 26.5 and $26.0 \%$ of controls, respectively. The weakest effects resulted from exposure to $\alpha$-pinene and the monoterpene mixture, which reduced growth to 34.0 and $34.5 \%$ of controls, respectively (Table 3).

Dry weight. Across all treatments, dry weights were 8.1 to $19.0 \%$ of controls for F. temperatum and 9.0 to $26.5 \%$ of controls for $F$. circinatum (Table 4). ANOVA revealed the main effects of isolate and treatment on dry weight to be significant $(P<0.001$ in both cases). The effects of block, replication, and all interactions were not significant $(P \geq 0.999)$. Averaged across treatments, the greatest reduction in dry weight occurred in $F$. temperatum ( $11.7 \%$ of control), and all isolates of $F$. circinatum were significantly less affected $(P<0.05)$. Averaged across isolates, the largest effect on dry weight was caused by camphene and the least by $\alpha$-pinene (Table 4 ). Whereas each individual monoterpene 
TABLE 4. Dry weight of Fusarium circinatum and F. temperatum in the presence of monoterpenes

\begin{tabular}{|c|c|c|c|c|c|c|c|}
\hline \multirow[b]{2}{*}{ Isolate $^{w}$} & \multicolumn{7}{|c|}{ Control $(\%)^{\mathrm{x}}$} \\
\hline & $\alpha$-Pinene & $\beta$-Pinene & Limonene & Myrcene & Camphene & Mixture & Isolate mean ${ }^{\mathrm{y}}$ \\
\hline GL 56 & $20.9( \pm 0.01) \mathrm{ab}$ & $21.2( \pm 0.01) \mathrm{a}$ & $19.9( \pm 0.02) \mathrm{a}$ & $20.3( \pm 0.02) \mathrm{a}$ & $14.4( \pm 0.02) \mathrm{ab}$ & $19.9( \pm 0.01) \mathrm{a}$ & $19.4( \pm 0.01) \mathrm{a}$ \\
\hline GL 58 & $26.3( \pm 0.03) \mathrm{a}$ & $17.5( \pm 0.01) \mathrm{ab}$ & $16.4( \pm 0.03) \mathrm{ab}$ & $19.9( \pm 0.03) \mathrm{a}$ & $13.4( \pm 0.03) \mathrm{abc}$ & $19.2( \pm 0.02) \mathrm{a}$ & $18.8( \pm 0.01) \mathrm{ab}$ \\
\hline GL 1321 & $21.2( \pm 0.01) \mathrm{ab}$ & $19.4( \pm 0.01) \mathrm{a}$ & $17.7( \pm 0.00) a b$ & $19.6( \pm 0.00) \mathrm{a}$ & $15.3( \pm 0.00) \mathrm{a}$ & $18.3( \pm 0.01) \mathrm{a}$ & $18.6( \pm 0.01) \mathrm{ab}$ \\
\hline GL 1325 & $24.7( \pm 0.03) \mathrm{ab}$ & $15.5( \pm 0.02) \mathrm{abc}$ & $14.0( \pm 0.02) \mathrm{abcd}$ & $16.7( \pm 0.02) \mathrm{ab}$ & $13.4( \pm 0.02) \mathrm{abc}$ & $20.2( \pm 0.05) \mathrm{a}$ & $17.4( \pm 0.01) b$ \\
\hline GL 290 & $17.9( \pm 0.02) b$ & $15.9( \pm 0.03) \mathrm{ab}$ & $15.9( \pm 0.00) a b c$ & $17.5( \pm 0.00) \mathrm{ab}$ & $11.2( \pm 0.00) \mathrm{abc}$ & $15.5( \pm 0.01) \mathrm{a}$ & $15.6( \pm 0.01) \mathrm{c}$ \\
\hline GL 1326 & $26.5( \pm 0.00) \mathrm{a}$ & $11.8( \pm 0.03) b c$ & $9.8( \pm 0.01) \mathrm{cd}$ & $11.9( \pm 0.01) b c$ & $13.1( \pm 0.01) \mathrm{abc}$ & $20.0( \pm 0.04) \mathrm{a}$ & $15.5( \pm 0.02) \mathrm{c}$ \\
\hline GL 100 & $17.3( \pm 0.03) b$ & $16.6( \pm 0.02) \mathrm{ab}$ & $13.3( \pm 0.01)$ abcd & $17.3( \pm 0.01) \mathrm{ab}$ & $13.3( \pm 0.01) \mathrm{abc}$ & $14.4( \pm 0.01) \mathrm{a}$ & $15.4( \pm 0.01) \mathrm{c}$ \\
\hline GL 311 & $16.9( \pm 0.01) b$ & $17.8( \pm 0.00) \mathrm{a}$ & $14.4( \pm 0.04)$ abcd & $14.8( \pm 0.04) \mathrm{abc}$ & $12.1( \pm 0.04) \mathrm{abc}$ & $14.4( \pm 0.00) \mathrm{a}$ & $15.1( \pm 0.01) \mathrm{c}$ \\
\hline GL 301 & $14.9( \pm 0.01) b$ & $16.5( \pm 0.01) \mathrm{ab}$ & $14.9( \pm 0.02) \mathrm{abc}$ & $15.9( \pm 0.02) \mathrm{abc}$ & $12.8( \pm 0.02) \mathrm{abc}$ & $15.3( \pm 0.01) \mathrm{a}$ & $15.0( \pm 0.00) \mathrm{c}$ \\
\hline GL 314 & $19.2( \pm 0.00) \mathrm{ab}$ & $10.8( \pm 0.01) \mathrm{c}$ & $11.2( \pm 0.00) \mathrm{bcd}$ & $12.2( \pm 0.00) b c$ & $9.0( \pm 0.00) b c$ & $17.7( \pm 0.01) \mathrm{a}$ & $13.4( \pm 0.01) \mathrm{d}$ \\
\hline GL 52 & $19.0( \pm 0.01) \mathrm{ab}$ & $8.1( \pm 0.01) \mathrm{d}$ & $8.4( \pm 0.01) \mathrm{d}$ & $10.6( \pm 0.01) \mathrm{c}$ & $8.3( \pm 0.01) \mathrm{c}$ & $16.0( \pm 0.01) \mathrm{a}$ & $11.7( \pm 0.01) \mathrm{e}$ \\
\hline Mean $^{2}$ & $20.3( \pm 0.01) \mathrm{A}$ & $17.3( \pm 0.01) \mathrm{B}$ & $15.9( \pm 0.01) \mathrm{C}$ & $15.3( \pm 0.01) \mathrm{C}$ & $12.3( \pm 0.00) \mathrm{E}$ & $14.0( \pm 0.00) \mathrm{D}$ & $\ldots$ \\
\hline
\end{tabular}

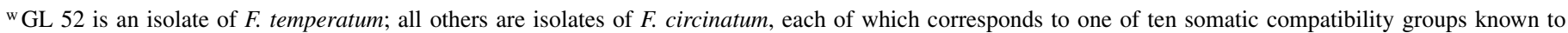
occur in California.

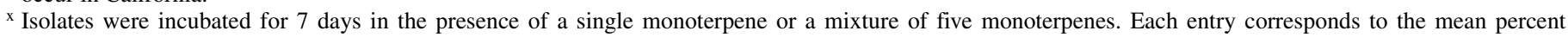
reduction in dry weight ( \pm standard error) relative to the same isolate not exposed to monoterpenes $(n=8)$. Means in the same column followed by a common lowercase letter were not significantly different at $P=0.05$, based on Tukey's all pairwise comparison test, which includes a correction for multiple comparisons.

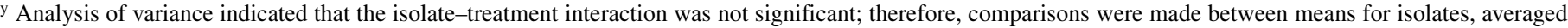
across treatments. Means followed by a common lowercase letter were not significantly different at $P=0.05$, based on Tukey's all pairwise comparison test, which includes a correction for multiple comparisons.

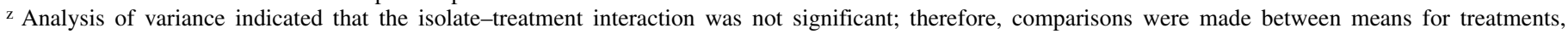
averaged across isolates. Means followed by the same uppercase letter were not significantly different at $P=0.05$, based on Tukey's all pairwise comparison test, which includes a correction for multiple comparisons.

TABLE 5. Survival in resin of spores of Fusarium circinatum and F. temperatum

\begin{tabular}{lc}
\hline Strain $^{\mathrm{y}}$ & Percent $^{\mathrm{z}}$ \\
\hline GL 56 & $100.0( \pm 0.0) \mathrm{a}$ \\
GL 311 & $100.0( \pm 0.0) \mathrm{a}$ \\
GL 100 & $100.0( \pm 0.0) \mathrm{a}$ \\
GL 1325 & $100.0( \pm 0.0) \mathrm{a}$ \\
GL 1326 & $100.0( \pm 0.0) \mathrm{a}$ \\
GL 58 & $100.0( \pm 0.0) \mathrm{a}$ \\
GL 290 & $88.3( \pm 3.0) \mathrm{a}$ \\
GL 301 & $88.3( \pm 3.0) \mathrm{a}$ \\
GL 314 & $97.0( \pm 3.0) \mathrm{a}$ \\
GL 1321 & $88.3( \pm 3.0) \mathrm{a}$ \\
GL 52 & $11.7( \pm 1.4) \mathrm{b}$ \\
\hline
\end{tabular}

y GL 52 is an isolate of $F$. temperatum; all others are isolates of $F$. circinatum, each of which corresponds to one of ten somatic compatibility groups known to occur in California.

z Percentage of filter disks from which growth emerged. Each disk, on which 100 spores were deposited, was immersed in resin for 7 days. Each entry corresponds to the mean ( \pm standard error) of three replications. Means followed by a common letter were not significantly different at $P=0.05$, based on Tukey's all pairwise comparison test, which includes a correction for multiple comparisons.

revealed significant differences between isolates $(P \leq 0.05)$, the monoterpene mixture did not (Table 4).

Spore survival in resin. Based on ANOVA, the effect of isolate on spore survival was significant $(P=0.004)$. The percentage of spores surviving in the presence of $P$. radiata resin was significantly lower for $F$. temperatum than for all isolates of $F$. circinatum (Table 5).

Intraspecific variation in $\boldsymbol{F}$. temperatum. Analysis of radial growth data for four isolates of $F$. temperatum (Table 1) and one isolate of $F$. circinatum (GL 58) in the presence of $\beta$-pinene showed the main effect of isolate to be significant $(P<0.001)$ and the effects of block, replication, and the block-isolate interaction not to be significant $(P \geq 0.2349)$. All isolates of $F$. temperatum, for which growth ranged from 7.7 to $12.7 \%$ of controls, were significantly less tolerant of $\beta$-pinene than $F$. circinatum (Fig. 2).

Virulence assays. In total, 10 trees were inoculated, 5 in each of two blocks. Trees in block one supported significantly longer lesions than trees in block two $(P<0.001)$. However, the blockisolate interaction was not significant $(P=0.848)$; therefore, data

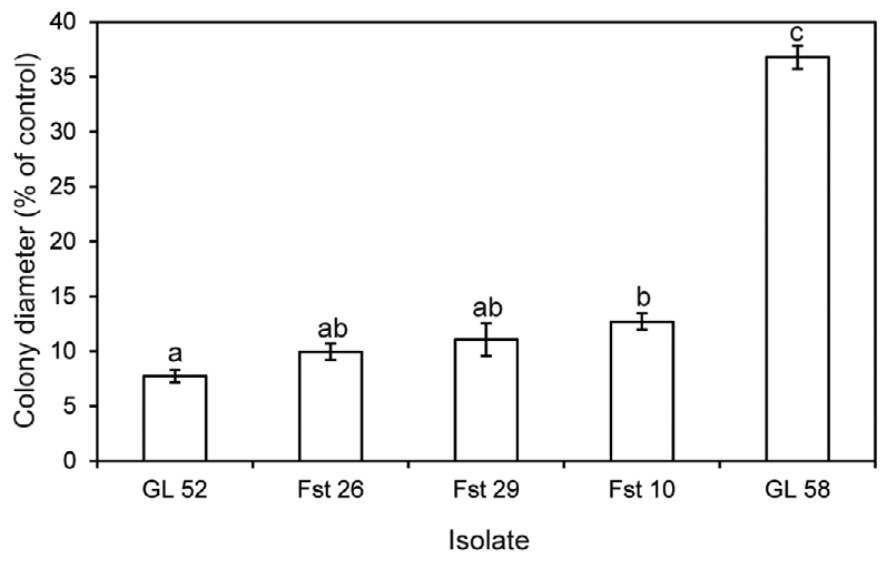

Fig. 2. Radial growth of Fusarium temperatum (Fst 10, Fst 26, Fst 29, and GL 52 ) and $F$. circinatum (GL 58) in a saturated atmosphere of $\beta$-pinene as a percentage of untreated controls. Isolates denoted with a common letter were not significantly different at $P=0.05$. Error bars correspond to $2 \times$ the standard error of the mean.

were pooled across blocks to compute mean lesion lengths for each isolate. F. temperatum was avirulent (mean lesion length \pm standard error $=2.7 \pm 0.4 \mathrm{~mm}$ ), whereas mean lesion lengths for isolates of $F$. circinatum were $19.0 \pm 2.3$ to $28.1 \pm 4.9 \mathrm{~mm}$ (Fig. 3 ). These values were used to test for correlations between virulence and tolerance of resin components, based on relative reductions in growth resulting from exposure to monoterpenes (Tables 3 and 4), as described below.

Regression analyses revealed a significant relationship between lesion length and tolerance of radial growth to $\alpha$-pinene $\left(R^{2}=\right.$ $0.414 ; P=0.033)$, limonene $\left(R^{2}=0.402 ; P=0.036\right)$, and camphene $\left(R^{2}=0.607 ; P=0.005\right)$. Similar trends were apparent for other monoterpenes but correlations with virulence were not significant for tolerance of radial growth to $\beta$-pinene $\left(R^{2}=0.360\right.$; $P=0.051)$, myrcene $\left(R^{2}=0.312 ; P=0.074\right)$, or the mixture of monoterpenes $\left(R^{2}=0.196 ; P=0.1728\right)$. When data for $F$. temperatum were excluded, regression analyses showed no significant relationship between virulence and tolerance of radial growth to any monoterpenes $(P \geq 0.461)$. With or without data for $F$. temperatum, there were no significant correlations between virulence 
and tolerance of resin components based on relative reductions in dry weight, and no significant correlations between virulence and growth in the absence of monoterpenes based on either dry weight or radial growth (data not shown).

To provide an independent test for a correlation between tolerance of monoterpene components of resin and virulence, the effect of $\beta$-pinene on radial growth was determined for progeny of a cross (Table 1) known to induce significantly different lesion lengths on susceptible Monterey pine trees (12). The results showed the effect of $\beta$-pinene on radial growth to be significant $(P<0.001)$ but there was not a significant relationship between radial growth in the presence of $\beta$-pinene and virulence to Monterey pine (Fig. 4).

\section{DISCUSSION}

Resin accumulation is a common response to wounding in pine and is presumed to contribute to defense against infection (11). If so, fungi capable of causing disease on pine trees would be expected to tolerate resin and the toxic components therein better than nonpathogenic strains. Consistent with this expectation, isolates of the pine pathogen $F$. circinatum were generally less affected by exposure to resin or to a saturated atmosphere of monoterpenes than isolates of the closely related nonpathogen $F$. temperatum.

The monoterpene of greatest abundance in $P$. radiata resin, (+) $\alpha$-pinene, had the least effect on dry weight accumulation (Table 4) and among the weakest effects on spore germination and radial growth (Tables 2 and 3). A racemic mixture was used in the present study, and it is possible that (+) and (-) enantiomers would differ in their inhibitory effects on $F$. circinatum or F. temperatum. Fäldt et al. (9) found a higher concentration of the $(-)$ enantiomers of $\alpha$-pinene, $\beta$-pinene, and limonene in trees after fungal inoculation, suggesting that this form may be more active against potential pathogens. They also observed that more virulent fungi induced greater qualitative and quantitative changes in monoterpene composition.

Spore germination rates in a saturated atmosphere of monoterpenes were relatively high for all tested isolates, including $F$. temperatum, which germinated at a lower rate than all but one isolate of $F$. circinatum. On the other hand, when placed in direct contact with resin, spore survival rates for $F$. circinatum were significantly higher than for $F$. temperatum. Thus, when spores were exposed only to the volatile components of resin, the differential effect on $F$. circinatum and $F$. temperatum was less apparent. A low rate of spore survival in the presence of resin can help to explain the inability of $F$. temperatum to cause disease in pine.

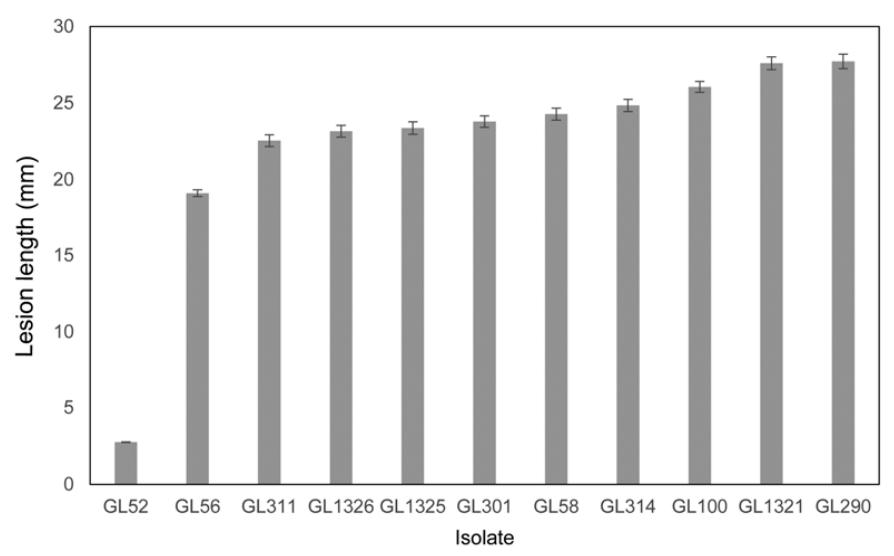

Fig. 3. Mean lesion lengths on Pinus radiata resulting from inoculation with Fusarium temperatum (GL 52) or F. circinatum (all others). Error bars correspond to $2 \times$ the standard error of the mean.
Eckhardt et al. (8) reported spore germination in the weakly pathogenic species Leptographium procerum to be more strongly affected by resin than more virulent species of Leptographium, although the magnitude of the difference was dependent on the pine species from which resin was obtained. Cobb et al. (5) reported little reduction in spore germination of the pathogenic Ceratocystis spp. Ceratocystis minor, C. schrenkiana, and C. ips (=Ophiostoma ips), caused by exposure to the same monoterpenes tested in this study, whereas spore germination of the nonpathogen $C$. pilifera was reduced by 20 to $25 \%$ in the presence of $\beta$-pinene and camphene.

Notwithstanding limited effects on spore germination, Cobb et al. (5) reported that germ tube elongation several hours after germination in Ceratocystis spp. was reduced by 20 to $70 \%$ in the presence of monoterpenes. Thus, growth appeared to be more sensitive to the effects of monoterpenes than spore germination. Likewise for both $F$. circinatum and $F$. temperatum, monoterpenes had a greater impact on growth than on spore germination. Growth reductions also clearly differentiated $F$. temperatum from F. circinatum. Based on both radial growth and biomass accumulation, exposure to monoterpenes had a significantly greater negative impact on $F$. temperatum than any isolate of $F$. circinatum.

All the monoterpenes tested revealed variation in growth among isolates of $F$. circinatum and clearly differentiated $F$. circinatum from $F$. temperatum isolate GL 52 (Table 3 ). $\beta$-pinene, one of the most abundant and inhibitory components of $P$. radiata resin, was selected to assess variation within $F$. temperatum, in order to gauge the extent to which GL 52 was representative of this species. There was significant variation in radial growth between isolates of $F$. temperatum exposed to $\beta$-pinene but all were significantly less tolerant of this monoterpene than $F$. circinatum (Fig. 2).

Overall, biomass accumulation was more severely affected than radial growth and the range of variation across isolates was narrower for the impact on dry weight (reduced to 9.4 to $11.7 \%$ of control) than on radial growth (16.9 to $39.4 \%$ of control). The reason for this differential effect is not known but could relate to the fact that fungi were exposed to monoterpenes as volatile components of the atmosphere in which they were growing. As a consequence, hyphae growing into the agar benefited from a barrier to diffusion that may have reduced exposure to monoterpenes. Thus, radial growth, which can be accomplished through hyphal extension within the substrate, may be less affected than mycelial growth above the surface.

As observed in other studies, $F$. temperatum was capable of only very limited growth when inoculated into pine branches (12),

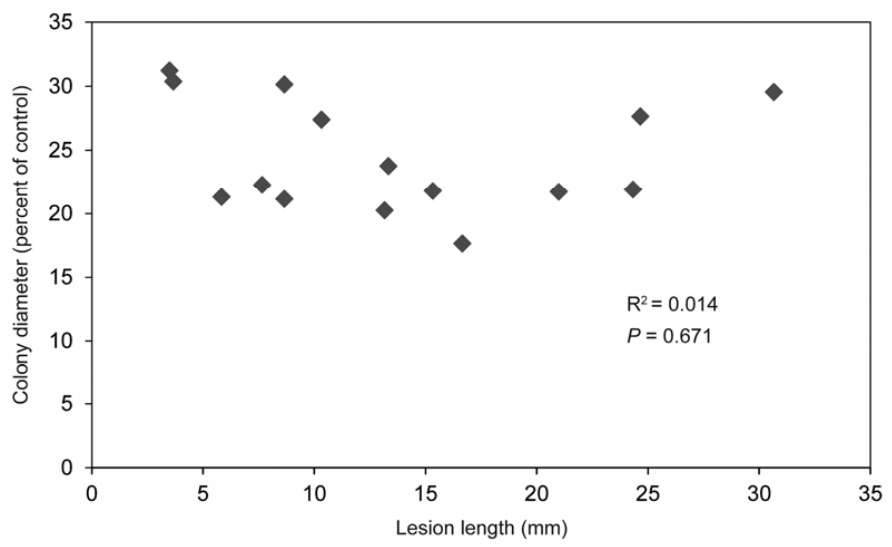

Fig. 4. Relationship between tolerance of $\beta$-pinene and virulence to pine. Each point corresponds to growth in a saturated atmosphere of $\beta$-pinene (as a percentage of an untreated control) and lesion length induced on Pinus radiata for one strain obtained from a cross between an $\mathrm{F}_{1}$ hybrid (Fusarium circinatum $\times F$. temperatum) and $F$. circinatum. 
whereas $F$. circinatum isolates manifested a range of virulence. Virulence (i.e., lesion length) was positively and significantly correlated with tolerance of radial growth to exposure to most monoterpenes but only when data for $F$. temperatum were included in the analyses. The absence of significant associations between lesion length induced by $F$. circinatum (Table 1 ) and the ability of to grow in the presence of monoterpenes may be due to insufficient variation in virulence among naturally occurring isolates of F. circinatum (Fig. 3). A wider range of virulence was manifest in progeny of a back cross between an $\mathrm{F}_{1}$ hybrid (from a cross between $F$. temperatum and $F$. circinatum) and $F$. circinatum (12) but, here again, there was not a significant correlation between tolerance of a monoterpene and lesion length induced on a susceptible pine.

The results of this research are consistent with the hypothesis that greater tolerance of resin is one factor required for virulence that distinguishes $F$. circinatum from the closely related $F$. temperatum. However, differential tolerance to monoterpene components of resin within $F$. circinatum cannot explain the observed variation in virulence to pine. Other characteristics that may be important in this regard include tolerance of nonvolatile components of resin and pathogenicity factors produced by the fungus such as enzymes and toxins.

\section{ACKNOWLEDGMENTS}

We thank Z. Blumenfeld for technical assistance and R. M. Bostock and two anonymous reviewers for many helpful comments on this manuscript.

\section{LITERATURE CITED}

1. Andrews, R. E., Parks, L. W., and Spence, K. D. 1980. Some effects of Douglas-fir terpenes on certain microorganisms. Appl. Environ. Microbiol. 40:301-304.

2. Bostock, R. M., and Stermer, B. A. 1989. Perspectives on wound-healing in resistance to pathogens. Annu. Rev. Phytopathol. 27:343-371

3. Burdon, R. D., Gaskin, R. E., Zabkiewicz, J. A., and Low, C. B. 1992. Genetic survey of Pinus radiata: 7. Variations and inheritance of pinene composition in wood oleoresin. N. Z. J. For. Sci. 22:246-256.

4. Burdon, R. D., Zabkiewicz, J. A., and Andrew, I. A. 1992. Genetic survey of Pinus radiata: 8. Population differences in monoterpene composition of cortical oleoresin. N. Z. J. For. Sci. 22:257-273.

5. Cobb Jr., F. W., Kristic, M., Zavarin, E., and Barber, H. W., Jr. 1968. Inhibitory effects of volatile oleoresin components on Fomes annosus and four Ceratocystis species. Phytopathology 58:1199-1324.

6. Coppen, J. J. W., and Robinson, J. M. 1988. Terpenoid constituents and properties of xylem oleoresin from exotic Pinus radiata. Naval Stores Rev. Mar/April:12-14.

7. Desjardins, A. E., Plattner, R. D., and Gordon, T. R. 2000. Gibberella fujikuroi mating population A and Fusarium subglutinans from teosinte species and maize from Mexico and Central America. Mycol. Res. 104:865-872.

8. Eckhardt, L. G., Menard, E. D., and Gray, E. D. 2009. Effects of oleoresins and monoterpenes on in vitro growth of fungi associated with pine decline in the southern United States. For. Pathol. 39:157-167.

9. Fäldt, J., Solheim, H., Långström, B., and Borg-Karlson, A. K. 2006. Influence of fungal infection and wounding on contents of enantiomeric composition of monoterpenes in phloem of Pinus sylvestris. J. Chem. Ecol. 32:1779-1795.
10. Flores, F., El Yahyaoui, F., de Billerbeck, G., Romojaro, F., Latche, A., Bouzayen, M., Pech, J. C., and Ambid, C. 2002. Role of ethylene in the biosynthetic pathway of aliphatic ester aroma volatiles in Charentais Cantaloupe melons. J. Exp. Bot. 53:201-206.

11. Franceschi, V. R., Krokene, P., Christiansen, E., and Krekling, T. 2005. Anatomical and chemical defenses of conifer bark against bark beetles and other pests. New Phytol. 167:353-376.

12. Friel, C. J., Desjardins, A. E., Kirkpatrick, S. C., and Gordon, T. R. 2007. Evidence for recombination and segregation for virulence to pine in a hybrid cross between Gibberella circinata and G. subglutinans. Mycol. Res. 111:827-831

13. Gordon, T. R., Kirkpatrick, S. C., Aegerter, B. J., Wood, D. L., and Storer, A. J. 2006. Susceptibility of Douglas-fir (Pseudotsuga menziesii) to pitch canker, caused by Gibberella circinata (anamorph $=$ Fusarium circinatum). Plant Pathol. 55:231-237.

14. Gordon, T. R., Okamoto, D., Storer, A. J., and Wood, D. L. 1998. Susceptibility of five landscape pines to pitch canker disease, caused by Fusarium subglutinans f. sp. pini. HortScience 33:868-871.

15. Gordon, T. R., Storer, A. J., and Okamoto, D. 1996. Population structure of the pitch canker pathogen, Fusarium subglutinans f. sp. pini, in California. Mycol. Res. 100:850-854.

16. Gordon, T. R., Storer A. J., and Wood, D. L. 2001. The pitch canker epidemic in California. Plant Dis. 85:1128-1139.

17. Gordon, T. R., Wikler, K. R., Clark, S. L., Okamoto, D., Storer, A. J., and Bonello, P. 1998. Resistance to pitch canker disease, caused by Fusarium subglutinans f. sp. pini, in Monterey pine (Pinus radiata). Plant Pathol. 47:706-711.

18. Hepting, G. H., and Roth, E. R. 1946. Pitch canker, a new disease of some southern pines. J. For. 44:742-744.

19. Komada, H. 1975. Development of a selective medium for quantitative isolation of Fusarium oxysporum from natural soils. Rev. Prot. Res. 8:114-125.

20. Marei, G. K., Abdel Rasoul, M. A., and Abdelgaleil, S. A. M. 2012. Comparative antifungal activities and biochemical effects of monoterpenes on plant pathogenic fungi. Pestic. Biochem. Physiol. 103:56-61.

21. Martín-Rodrigues, N., Espinel, S., Sanchez-Zabala, J., Ortíz, A., Gonzalez-Murua, C., and Duñabeitia, N. K. 2013. Spatial and temporal dynamics of the colonization of Pinus radiata by Fusarium circinatum, of conidiophora development in the pith and of traumatic resin duct formation. New Phytol. 198:1215-1227.

22. Phillips, M. A., and Croteau, R. B. 1999. Resin-based defenses in conifers. Trends Plant Sci. 4:184-190.

23. Scauflaire, J., Gourgue, M., and Munaut, F. 2011. Fusarium temperatum sp. nov. from maize, an emergent species closely related to Fusarium subglutinans. Mycologia 103:586-597.

24. Smith, R. H. 2000. Xylem monoterpenes of pines: Distribution, variation, genetics, function. For. Serv. Gen. Tech. Rep. PSW-GTR-177, U.S. Dep. Agric. Washington, DC.

25. Strauss, S. H., and Critchfield, W. B. 1982. Inheritance of beta-pinene in xylem oleoresin of Knobcone $\times$ Monterey pine hybrids. For. Sci. 28:687696.

26. Stein, S. 2012. Mass spectral reference libraries: An ever-expanding resource for chemical identification. Anal. Chem. 84:7274-7282.

27. Swett, C. L., and Gordon, T. R. 2009. Colonization of corn (Zea mays) by the pitch canker pathogen, Fusarium circinatum: Insights into the evolutionary history of a pine pathogen. (Abstr.) Phytopathology 99:S126.

28. Swett, C. L., and Gordon, T. R. 2012. First report of grass species (Poaceae) as naturally occurring hosts of the pine pathogen Gibberella circinata. Plant Dis. 96:908.

29. Uribe, S., Ramirez, J., and Pena, A. 1985. Effects of $\alpha$-pinene on yeast membrane function. J. Bacteriol. 161:1195-1200.

30. Wallis, C., Eyles, A., Chorbadjian, R., Riedel, K., Schwartz, S., Hansen, R., Cipollini, D., Herms, D., and Bonello, P. 2008. Systemic induction of phloem secondary metabolism and its relationship to resistance to a canker pathogen in Austrian pine. New Phytol. 177:767-778. 